\title{
Scaling up breastfeeding policy and programs in Samoa: application of the Becoming Breastfeeding Friendly initiative
}

\author{
Christina Soti-Ulberg ${ }^{1 *}$, Amber Hromi-Fiedler ${ }^{2}$, Nicola L. Hawley², Take Naseri', Analosa Manuele-Magele ${ }^{1}$,
} John Ah-Ching ${ }^{1}$, Rafael Pérez-Escamilla ${ }^{2}$ and on behalf of BBF Samoa Committee

\begin{abstract}
Background: Breastfeeding is a critical, evidence-based intervention that addresses malnutrition, improves early childhood development outcomes, and influences long-term maternal and infant health by reducing the noncommunicable disease risk. Scaling up breastfeeding is an indisputably strong action countries can take to prevent suboptimal maternal and infant health outcomes. The Becoming Breastfeeding Friendly (BBF) initiative assists countries with scaling up breastfeeding policy and programs. BBF has been successfully implemented within Latin America, Africa, Europe and South-East Asian regions. This study assessed its application in Samoa.

Methods: In 2018, BBF was implemented in Samoa by a 20 member committee of breastfeeding experts who participated in collecting and utilizing national level data to score the degree of friendliness of Samoa's breastfeeding environment, identify gaps, and propose policy recommendations to address those gaps. This eightmonth process resulted in a public event where priority recommendations were widely disseminated to decision makers and actions agreed upon.

Results: The total BBF Index score for Samoa was 1.6 out of 3.0, indicating a moderate breastfeeding friendly environment for scaling up policies and programs that protect, promote, and support breastfeeding. Gear total scores indicated that seven of the eight gears were moderately strong within Samoa, while the eighth gear, funding and resources, was weakest in strength. Six prioritized recommendations emerged: 1) development and implementation of a National Breastfeeding Policy and Strategic Action Plan; 2) strengthening monitoring and evaluation of all breastfeeding activities; 3 ) ratifying the International Labour Organization's Maternity Protection Convention 2000 (No 183); 4) identifying high-level advocates to champion and serve as role models for breastfeeding; 5) creation of a national budget line for breastfeeding activities; and 6) hiring of a national breastfeeding coordinator and trainer. Decision makers demonstrated commitment by signing the breastfeeding policy for hospitals ahead of the BBF dissemination meeting and electing to move forward with establishing lactation rooms within government ministries.
\end{abstract}

Conclusion: Implementation of BBF in Samoa yielded important policy recommendations that will address current gaps in national level breastfeeding support. The BBF consultation process can be successfully applied to other countries within the Western Pacific region in order to strengthen their breastfeeding programs.

Keywords: Breastfeeding, Samoa, Becoming Breastfeeding Friendly, Scaling up

\footnotetext{
* Correspondence: tina.ulberg@gmail.com

${ }^{1}$ Ministry of Health, Apia, Samoa

Full list of author information is available at the end of the article
}

(c) The Author(s). 2020 Open Access This article is distributed under the terms of the Creative Commons Attribution 4.0 International License (http://creativecommons.org/licenses/by/4.0/), which permits unrestricted use, distribution, and reproduction in any medium, provided you give appropriate credit to the original author(s) and the source, provide a link to the Creative Commons license, and indicate if changes were made. The Creative Commons Public Domain Dedication waiver (http://creativecommons.org/publicdomain/zero/1.0/) applies to the data made available in this article, unless otherwise stated. 


\section{Background}

Breastfeeding is a 'triply-duty action' that has demonstrated immense potential as an evidence-based intervention to address malnutrition in all its forms (i.e. underweight, stunting, micronutrient deficiencies, overweight, and obesity) while also improving early childhood development outcomes [1]. Undeniably, the early benefits of breastfeeding extend throughout the life course to protect the health of a mother and her infant further by reducing the longer term risk of certain cancers and other chronic diseases [2]. For countries that face considerable concerns associated with the presence of multiple forms of malnutrition plus increasing prevalence of noncommunicable diseases (NCDs), scaling up national breastfeeding policies and programs can be a cost-saving strategy [3] to avoid overwhelming health care costs associated with these conditions [4]. Indeed, the cost of inaction (i.e. not breastfeeding) can lead to significant human capital, economic, and environmental loses for a country [5]. Unfortunately, countries committed to scaling up breastfeeding friendly environments have been challenged by frameworks that are limited and lack effectiveness as well as few valid decision-making tools [6].

Becoming Breastfeeding Friendly (BBF) is an evidenceinformed initiative that addresses this gap by providing countries with a valid toolbox to assess and develop a plan to scale up national policies and programs to strengthen the breastfeeding friendly enabling environment [7]. Becoming Breastfeeding Friendly is grounded in the Breastfeeding Gear Model framework, which uses a complex adaptive systems approach to stipulate that eight gears - advocacy; political will; legislation \& policy; funding \& resources; training \& program delivery; promotion; research \& evaluation; coordination, goals \& monitoring - must work in harmony to achieve large-scale improvements in a country's breastfeeding friendly environment [8]. The BBF toolbox consists of a BBF index (BBFI), case studies, and a 5-meeting process [9]. Application of the BBF toolbox is expected to drive policy changes within a country, subsequently strengthening the breastfeeding environment following the cyclical policy heuristic model that includes five key elements: (a) leadership and partnerships; (b) agenda setting; (c) policy formulation and adoption; (d) implementation; and (e) evaluation [9, 10]. Ideally, by strengthening each of these elements, the BBF toolbox contributes to strengthening the friendliness of the breastfeeding environment through its repeated application across time $[9,10]$.

Over the past few years, BBF has been successfully implemented in countries in Latin America [11], Africa $[12]$, and Europe $[13,14]$. Yet, until last year, it had not been applied to a country in the Western Pacific region. Samoa served as an ideal setting to pilot the implementation of BBF within that region because of the country's ongoing partnership with the BBF lead university, Yale, and their commitment to maternal child health research and policy making. Indeed, the country had already demonstrated commitment to improving breastfeeding outcomes, as evidenced by the prominence of breastfeeding promotion in their National Health Strategy [15]. Plus, they had expressed a need to receive guidance on how to strategically move forward improving the coverage and quality of their breastfeeding programs.

Application of BBF in Samoa has wide-reaching implications for the Western Pacific region. Although breastfeeding is highlighted in many country health strategies and in the broader Action Plan for Healthy Newborn Infants in the Western Pacific Region [16], the prevalence of exclusive breastfeeding among infants less than 6 months of age varies widely across the Western Pacific region from more than $70 \%$ in the Solomon Islands to less than $40 \%$ in Tuvalu [17]. Guided by the World Health Organization regional office and the Secretariat of the Pacific Community, the Pacific Islands have demonstrated success in developing Pacific-wide strategies and monitoring plans for NCDs and infectious diseases. Following the implementation of BBF in Samoa, there is the potential for Samoa to take a leadership role in the dissemination of BBF to other Pacific nations and the development of a Pacific-wide strategy on breastfeeding promotion. Thus, the overarching objective of this manuscript is to describe the piloting and feasibility assessment of the BBF toolbox in Samoa, and document lessons learned for potential further dissemination in this region.

\section{Methods}

\section{Study site}

Samoa is an upper-middle income country located in the Western Pacific region with a population of $\sim 197,000$ and 6100 births each year [18]. Polynesia as a whole, and Samoa specifically, are recognized for their extremely high burden of chronic disease (93\% of women aged 25-64 are overweight or obese) [19] and concurrent issues of maternal and child malnutrition (one-third of women of reproductive age are anemic, 29\% of children aged 2-5 years are stunted, and 34\% anemic) [20], both of which may be positively impacted by improving breastfeeding practices. While uptake of breastfeeding is high ( $94 \%$ of all infants are breastfed) and median duration of breastfeeding is 21 months, exclusive breastfeeding declines after 2 months of age from 75 to $55 \%$ at $4-5$ months [18].

\section{BBF implementation in Samoa}

The Samoan Ministry of Health $(\mathrm{MOH})$ led the implementation of BBF between January-August 2018 on behalf of the Samoan government. Beginning in January 2018, preparations began with sensitizing key stakeholders to BBF, identifying a director to lead BBF implementation in Samoa, and identifying country committee members to 
participate in the 5-meeting process. In consultation with other government agencies (the Ministry of Women, Community, and Social Development (MWCSD), Ministry of Education, Sports, and Culture (MESC), Ministry of Commerce, Industry, and Labor (MCIL), and the Public Service Commission (PSC)) invitation letters to participate in the Samoan BBF country committee were sent by the $\mathrm{MOH}$ to the CEOs and heads of eight organizations representing government, academia, and non-governmental organizations. A country committee of 20 breastfeeding, lactation, and/or women's health experts from eight institutions (MOH, MCIL, PSC, MESC, Samoa Family Health Association, Samoa Red Cross, National University of Samoa, National Health Services) was established before the 5meeting process began.

In Samoa, the 1st meeting represented the formal indepth introduction of BBF to the BBF country committee members as well as government ministries and nongovernment key stakeholders. The 1st meeting educated BBF committee members about the BBFI, which is the primary assessment tool that measures the strength of a country's breastfeeding enabling environment through 54 individual benchmarks [7]. The 1st meeting also introduced participants to subsequent toolbox components, with the goal of empowering them to successfully implement BBF in their country [7]. Over 23 individuals attended, including the BBF Samoa co-investigator from Yale University (NLH), who also participated in most subsequent BBF meetings. Three aims were achieved during this 2-day meeting: a) introduced the current breastfeeding environment in Samoa, b) described the BBF toolbox components in detail, and c) initiated the assessment of the degree of friendliness of the breastfeeding environment with the BBFI. The latter included the formation of four teams of BBF committee members (5 members each) who worked on developing plans to gather data for the specific gears they were assigned to assess.

Following the first meeting, the four teams (i.e. gear teams) were tasked with identifying, collecting, and documenting local, district and national level data (i.e. national strategies, policies, legislation, survey data, media articles) relevant to scoring the benchmarks within their allocated gears. Gear teams met to discuss the data plus assign preliminary scores to their benchmarks. Indeed, each gear team held between two to five meetings throughout the 5meeting process to ensure benchmarks were fully assessed, scores assigned, and recommendations developed.

The BBF country committee reconvened 2 months later. At this 2nd meeting all gear teams, except the training \& program delivery gear team, presented their preliminary benchmark scores to the full committee. By the second meeting, the training \& program delivery gear team had not fully scored the requisite benchmarks and subsequently did not have scores to present. Instead, they presented their initial benchmark and gear scores at the 3rd meeting.

Across the seven gear team presentations at the 2nd meeting, the discussion centered around finding out: a) whether the benchmark scores reflected the available data, b) adequacy and gaps in the collected data, c) if consensus could be reached on the benchmark scores given the existing data, d) if additional data were required to reach consensus on the benchmark scores, and e) if any modifications in the initial recommendations were required at this point. In situations where the committee felt more data was required to score a benchmark, additional data was sought through in-depth interviews, reports, and other available sources. The quality of the data was considered by the committee during discussion and when reaching consensus on benchmark scores.

Following the 2nd meeting, gear teams independently obtained the remaining data, confirmed as well as adjusted benchmark scores based on available, additional collected data, and developed recommendations based on identified benchmark gaps. Benchmark scores for all gears were presented at the 3rd meeting in June 2018 where the BBF committee reached final consensus on the benchmark scores and subsequently calculated the gear scores as well as the total BBF score. Detailed recommendations were presented, discussed by gear, and revised to reflect the discussion.

In preparation for the 4th meeting, the BBF Samoa director (CSU) followed a multistep process developed by the BBF team at Yale to assist BBF committees with prioritizing their recommendations based on three key grading criteria: 1) effectiveness (i.e., will the recommendation have an effect or impact on breastfeeding outcomes), 2) affordability (i.e. is the recommendation affordable and are there the financial means to pay for it taking into account available information on the cost of implementing such a recommendation), and 3) feasibility (i.e. are all the necessary resources to implement such a recommendation present). Initially, the director combined recommendations that were duplicated across gears and then used the BBF case studies from the toolbox to provide supporting evidence for the recommendations. An online google survey was created and distributed to BBF committee members to answer questions to grade the effectiveness, affordability, and feasibility of each recommendation. Responses were collected, summed, and averaged so that each recommendation had an average score for each criterion (i.e. effectiveness, affordability, and feasibility) plus an overall average score.

The BBF committee reconvened 3 weeks later for the 4th meeting. At this one-day meeting, the director presented the survey results for each recommendation to 
the BBF committee. After an in-depth discussion, the committee felt the recommendations could be grouped into themes. Therefore, consensus was reached on the top six themes to represent their top overarching priority recommendations. Action plans for each prioritized recommendation were also developed to guide the future implementation of the recommendations. Discussion also ensued to identify which actions could be immediately addressed.

After the meeting, the prioritized recommendations and action plans were circulated to BBF committee members to finalize them. A one-page infographic was developed by the $\mathrm{MOH}$ nutrition unit under the director's supervision and contained a brief description of the: a) breastfeeding environment in Samoa prior to BBF implementation, b) BBF initiative, c) gear scores, and d) six prioritized recommendations. Additionally, a fourpage policy brief was also written by the Samoa leadership team in collaboration with the BBF team from Yale University to describe in more detail each topic within the infographic. Proposed actions were also included for each prioritized recommendation. Invitation letters were sent to government and non-government leaders as well as media personnel to attend the 5th meeting when BBF findings and policy recommendations would be disseminated.

On August 1, 2018, findings from the BBF initiative were disseminated in Samoa through a day long public event. The timing coincided perfectly with the beginning of World Breastfeeding Week and elicited attendance from over 100 individuals including high level decision makers from government ministries and health services, non-governmental organizations, and academia. The BBF PI and BBF Samoa co-investigator based at Yale University (RPE and NLH, respectively) also attended. The high level of government support was evident with the key note address being delivered by the Associate Minister of Health. The infographic and policy briefs were disseminated during the event to support the presentation of the findings and generate feedback and discussion among policymakers to reach consensus on the way forward.

\section{Results}

\section{BBFI gear scores}

The total BBFI score for Samoa was 1.6 out of a maximum of 3.0, indicating that the country had a moderately friendly breastfeeding environment for scaling up policies and programs that protect, promote, and support breastfeeding. Supporting this finding, the gear total scores indicated that seven of the eight gears were moderately strong within Samoa (Fig. 1). The funding and resources gear was the only gear that was assessed as being weak, which was primarily due to: a) lack of a national budget line for breastfeeding, b) lack of adequate funding and human resources for breastfeeding, c) lack of a national breastfeeding coordinator that is funded full time to primarily work on breastfeeding promotion, and d) having a limited formal mechanism for funding of maternity entitlements (Table 1).

\section{Prioritized recommendations}

Fifteen initial recommendations were generated at the second meeting based on the gaps identified by BBF committee members. Following the third meeting, those recommendations were expanded into twenty- three specific recommendations (Table 1). At the fourth meeting, six themes emerged from the 23 recommendations, representing the top priority recommendations.

The committee prioritized first the development and implementation of a National Breastfeeding Policy and Strategic Action Plan. The committee recommended that a National Breastfeeding Policy be drafted to include a strategic action plan and performance indicators. The committee felt several of the recommendations were important action items within this overarching recommendation. Specifically, the strategic plan needed to include actions on the: a) integration of breastfeeding into other health events during the year, b) acknowledgement of the endorsed Infant and Young Child Feeding Regulations and an annual work plan for related activities, c) development of an annual national symposium for breastfeeding, d) creation of a support network and service for breastfeeding free text messaging hotline, e) acknowledgement of breastfeeding champion(s) to highlight their important actions and facilitate support, and f) inclusion of all people in Samoa, including potentially vulnerable groups (e.g. disabled, abused, refugees, and people living with HIV). To ensure the policy and strategic action plan received support, committee members proposed that consultations be conducted with the $\mathrm{MOH}$ policy division on the feasibility of drafting a policy.

The committee prioritized strengthening the monitoring and evaluation of all breastfeeding activities. The proposed actions to build this capacity included: a) making data publicly available, specifically publishing collected data on breastfeeding practices online via websites such as the Ministry of Health, b) establishing a population-based surveillance or monitoring system to track breastfeeding/lactation counselling and support every 5 years, and c) strengthening routine data collection of breastfeeding outcomes during clinical and community outreach visits and provide quarterly and annual reporting.

For Samoa, ratifying the International Labour Organization's Maternity Protection Convention 2000 (No 183) [21] was also a top priority. The committee urged policymakers to discuss and approve provisions in the Maternity Protection Convention, especially: a) maternity protection against work that presents risks to the mother 


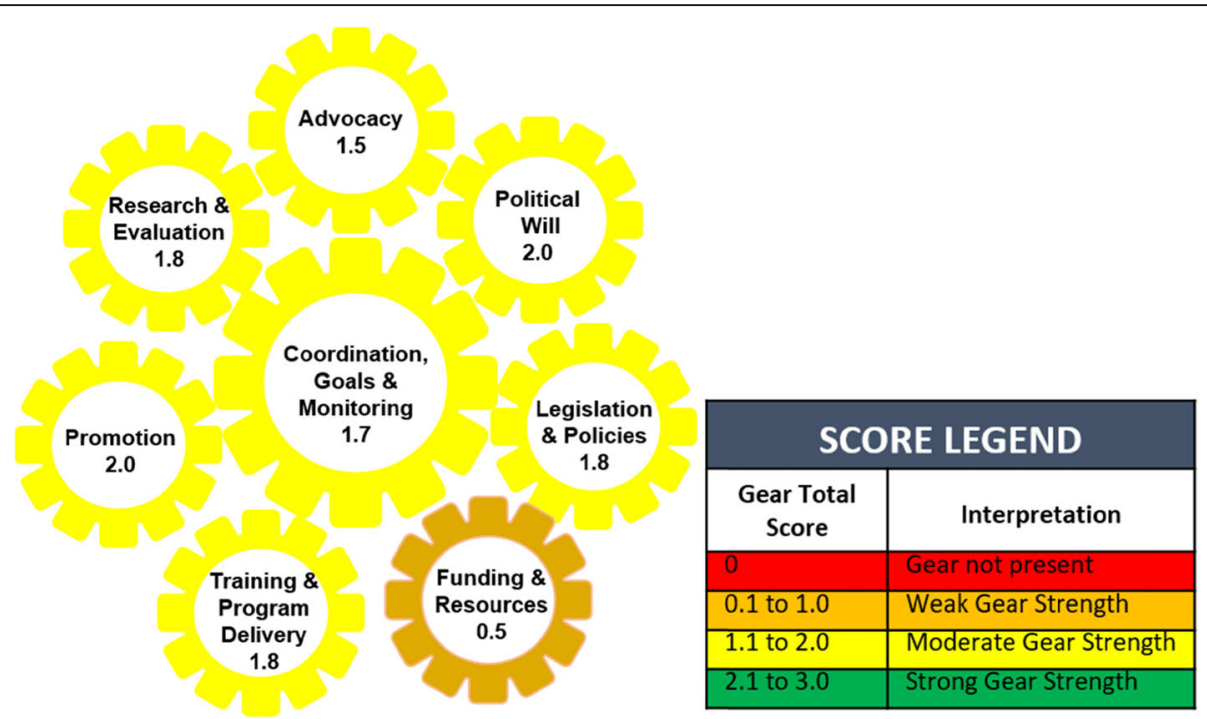

Fig. 1 The final eight gear scores for the Becoming Breastfeeding Friendly initiative in Samoa

or child's health, b) maternity leave that is more than 14 weeks with 6 weeks compulsory leave after childbirth, c) prenatal period of leave that is extended between the presumed date of birth and actual date without reducing the compulsory portion of postpartum leave, d) extending cash benefits and employment protection, and 5) establishing breastfeeding breaks at work. To strengthen the breastfeeding friendly environment in Samoa, the committee also felt that the government should establish a formal mechanism that would provide maternity entitlements for all working women. Essentially, it was suggested that the government subsidize maternity leave for the private sector to extend the current maternity leave benefits provided to these mothers from 4 weeks to 8 weeks.

The committee assessment identified several gaps related to the advocacy gear with the primary gap being that there were no high level, non-governmental advocates or influential individuals who had taken on breastfeeding as a cause that they are promoting. Thus, one of the committee's top recommendations was to identify high level advocates that will champion and serve as role models for breastfeeding. Specifically, the committee felt it was important to take steps to: a) identify local and global champions, b) train and involve champions in breastfeeding-related activities, and c) share success stories with the community via different media outlets (e.g., TV, documentary, Radio and/or Social Media/Facebook).

The committee prioritized two recommendations to strengthen the major gaps found in the funding \& resources gear. First, the committee determined that the creation of a national budget line for breastfeeding activities was essential. The committee proposed actions to develop a proposal for a national budget line that aligns with the future National Breastfeeding Policy and
Strategic Action Plan and allocates funds to specific breastfeeding activities including: a) the National Breastfeeding Program, b) the Baby Friendly Hospital Initiative (BFHI)/ Ten Steps, c) monitoring and enforcement of the International Code of Marketing of Breast Milk Substitutes, d) maternity protection, e) breastfeeding related information, education and communication campaigns and materials, and f) breastfeeding training and program delivery. Lastly, the committee proposed activities to support this priority recommendation including identifying the cost of key activities for breastfeeding advocacy, promotion, education, and training every fiscal year for allocation within the proposed budget line.

The committee also prioritized the hiring of a national breastfeeding coordinator and trainer. The committee proposed specific required activities to complete the hiring of a national breastfeeding coordinator who would be responsible for coordination of the BFHI/Ten Steps initiative as well as training of lactation counselors/master trainers. In addition to developing a job description, the committee specified the recruitment, selection, and training of a national coordinator/trainer as being essential to ensuring that this position is fully functional and that it can support the scaling up of national breastfeeding programs. The committee clearly indicated that the training-the-trainer recommended cascade had to include the following core functions: a) implement BFHI, b) in-service training for staff in maternity service, c) conduct hands-on training involving individual counseling for lactation issues, d) certify breastfeeding counseling training program by the Samoa Qualification Authority (SQA), e) coordinate professional development for breastfeeding, and $\mathrm{f}$ ) advocate for preservice curriculum to include breastfeeding and be uniform for all relevant schools including nursing and medicine. 


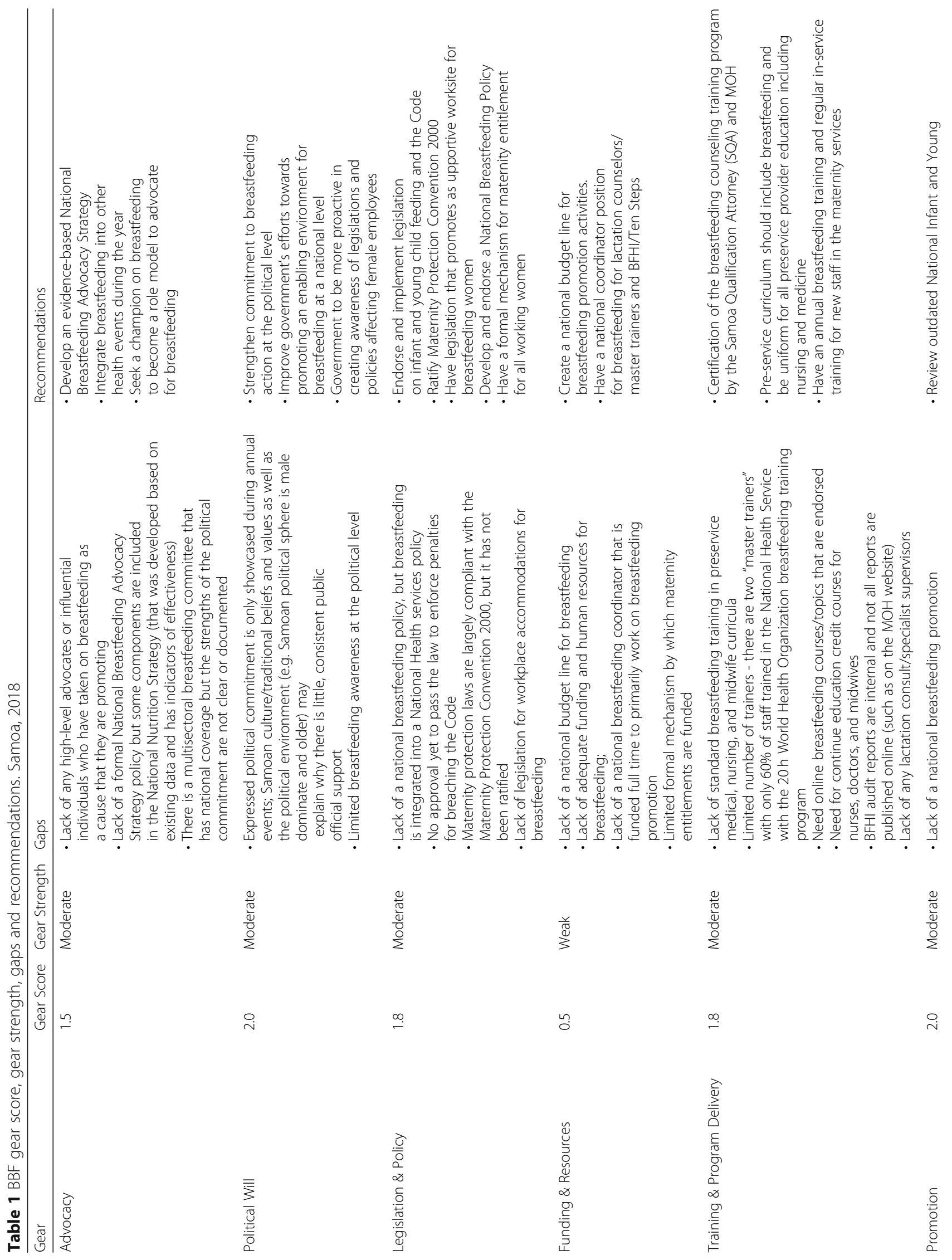


Soti-Ulberg et al. International Breastfeeding Journal

(2020) 15:1

Page 7 of 10

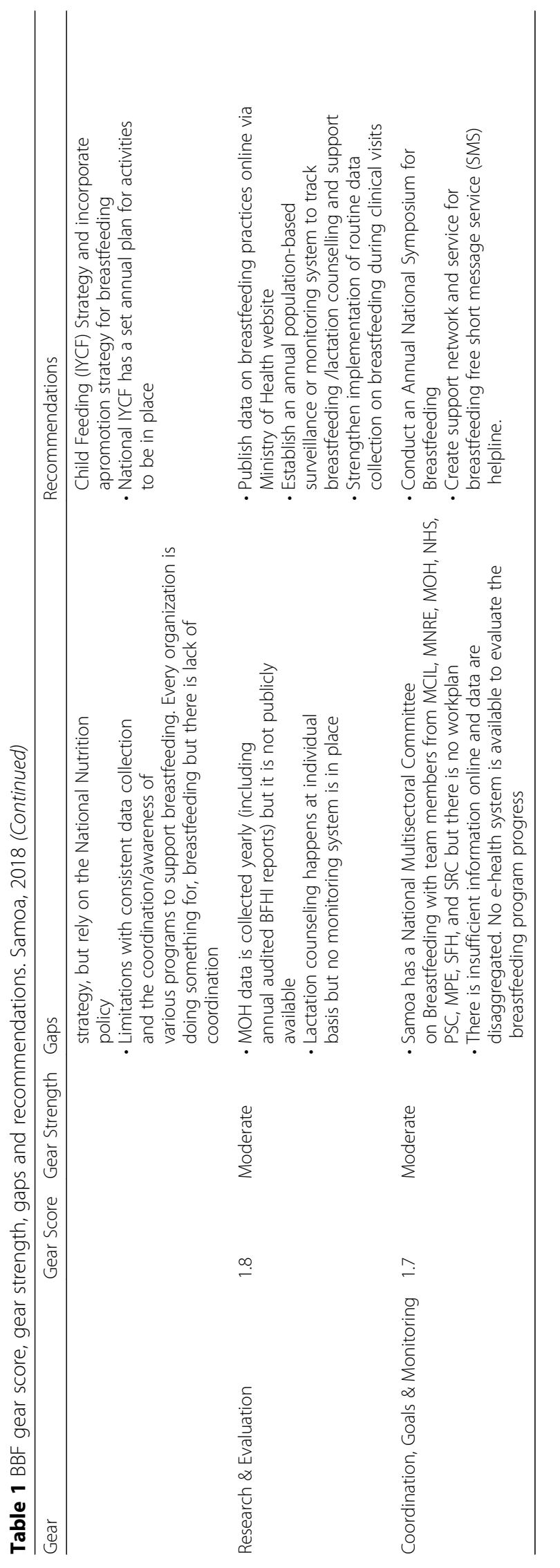




\section{Feasible action plans}

At the fourth meeting, the BBF committee identified the signing of an updated and revised breastfeeding policy for hospitals (originally a policy in 1995) as an immediate action that could begin to address some of the gaps.

\section{Commitments from decision makers}

Consensus was reached during the public event that the six prioritized recommendations were justified. Discussion centered around which recommendations to address first including the extension of maternity leave for the formal sector, providing financial support for maternity leave for the informal sector, building capacity by investing in training lactation specialists in Samoa, breastfeeding education and promotion in the community, and strengthening workplace environment to become breastfeeding friendly.

Decision makers demonstrated their commitment to strengthen breastfeeding in Samoa in two ways. First, the director general signed a revised and updated breastfeeding policy for hospitals and it was launched at this event. Second, various ministries including $\mathrm{MOH}, \mathrm{MCIL}$, MESC, agreed to begin with implementing the most feasible recommendations while also planning for those that would require a longer implementation timeframe. Decision makers thus committed to implementing one resolution that was deemed as most feasible. Decision makers renewed their commitment to implement a 2011 mandate instructing each ministry to establish a lactation room that provided a refrigerator for breastmilk, pumping station, and chair to allow mothers a safe environment to breastfeed. A representative from the MCIL put forth the suggestion to create an environment for their workplace resulting in an agreement across ministries to create breastfeeding friendly workplaces through the implementation and enforcement of breastfeeding spaces within government ministries. The MCIL and $\mathrm{MOH}$ elected to pilot the program and provide funding from their budget with the goal of being the role model for other ministries to move forward with establishing lactation rooms for their employees. It was decided that once all ministries had lactation rooms, the private sector would be approached to being working with them to establish breastfeeding friendly environments within their workspaces. To date, the $\mathrm{MOH}$ has established a lactation room within the Ministry and is working to establish others.

\section{Discussion}

For Samoa, implementing BBF has demonstrated their further commitment to strengthening their breastfeeding friendly environment. For the first time, BBF brought together a diverse group of stakeholders from across Samoa invested in strengthening the breastfeeding environment in the country. The gathering of stakeholders to dialogue and reach consensus on the top recommendations is an essential process to garner support, cooperation, and lead to the acceptance and implementation of the recommendations. Within Samoa, this process led to the full support of six priority recommendations to strengthen the breastfeeding friendly environment, increasing the likelihood that there would be movement towards policy implementation. Indeed, it was at the launching of the BBF recommendations that the updated breastfeeding policy was signed after years of trying to garner support from all key parties. To date, the signing of the breastfeeding policy along with BBF committee network efforts has led to the achievement of $80 \%$ of the BFHI Ten Steps in the two main hospitals in Samoa. These outcomes document the value of BBF across Samoa and is echoed among all other pretested BBF countries.

The implementation of BBF in Samoa identified clear key gaps within the breastfeeding environment that required strengthening to initiate the scaling up of breastfeeding policy and programs in the country. Samoa's lack of a specific budget line assigned to breastfeeding programs is not unique as other countries, including Mexico [11] and Ghana [12], have demonstrated similar results. Funding and resources are needed to drive the training of health care providers to deliver high-level breastfeeding support and education plus promote breastfeeding through various channels [8]. However, this financial commitment to national breastfeeding programs must come from the government to help countries try to reduce reliance on external funding to sustain breastfeeding programs [8].

Samoa emerged with a rich set of priority recommendations aimed at strengthening their breastfeeding friendly environment. Similar to Mexico [11], the resolution that decision makers felt was most feasible to first commit to was the establishment of lactation rooms within the public sector, primarily ministries. Improving the workplace environment has been shown to improve exclusive breastfeeding rates, with more services increasing rates in a doseresponse manner [22]. By taking a first step to strengthen the workplace environment, Samoa is demonstrating their commitment to strengthening maternity protection; an action which has the potential to encourage additional changes that can reap long-term rewards in promoting breastfeeding and improving breastfeeding outcomes.

Several lessons were learned during the implementation of BBF in Samoa. First, for countries planning to implement $\mathrm{BBF}$, an in-country director is needed to lead and coordinate BBF [9]. Therefore, it is essential to include BBF into the director's annual workplan so that is a planned responsibility rather than an added one. Within Samoa, BBF was an added responsibility thus the director found it challenging to set aside time to fully implement BBF given the additional duties and roles that 
person was responsible for within the $\mathrm{MOH}$. While support staff provided technical assistance to organize meetings, develop policy briefs and infographics, and collect data, the time commitment required by the director to lead BBF was extensive.

Second, building on Ghana's experience [12], having motivated breastfeeding experts who can devote the time to implementing BBF was essential to completing BBF within Samoa. Within Samoa, BBF committee members were highly diverse in their backgrounds as well as expert in one of the key gears, subsequently they were able to provide strong support, such as guidance and data, for the gears. Additionally, members were supportive of breastfeeding initiatives and thus motivated to complete BBF accurately and on-time. This supports the BBF guidance that selecting committee members is an essential component leading to the successful implementation of BBF [9].

Third, more gear team meetings may be needed to assist with the transfer of information and data plus to ensure accurate scoring of benchmarks and gears. Within Samoa, the operational manual was expansive and challenging for committee members to familiarize themselves with and use. Additionally, committee members were limited in their ability to access the BBF Dropbox (used to share data and scoring between gear members and the director) due to weak or no internet access at their workplaces. Frequent gear team meetings helped assure that the benchmarks were understood, the needed data was collected and shared, and scoring was accurate.

Fourth, continual information sharing ensured that high level decision makers were informed throughout the BBF process. The director shared information with gear teams through email groups, which ensured all gear members and their respective organizations plus the heads of governments ministries were informed about the progress of the BBF committee meetings and resolutions throughout the process. This too supports the BBF guidance that continual engagement of decision makers throughout the process is critical to the implementation of BBF recommendations [9].

\section{Conclusion}

In conclusion, the implementation of BBF in Samoa yielded some similar results as Mexico and Ghana. Decision makers identified similar areas to initially target and strengthen the breastfeeding environment plus some common lessons were learned. Samoa did show there was a need to adapt BBF to meet specific needs including time and technology challenges, yet these are not context specific and can be considered within countries facing these limitations. Such results have important implications as Samoa's successful implementation of BBF indicates that this initiative can be applied to other countries within the Western Pacific region that are also motivated to strengthen their breastfeeding environment.

\section{Abbreviations}

BBF: Becoming Breastfeeding Friendly; BFGM: Breastfeeding Gear Model; BFHI: Baby Friendly Hospital Initiative; MCIL: Ministry of Commerce, Industry, and Labor; MESC: Ministry of Education, Sports, and Culture; $\mathrm{MOH}$ : Ministry of Health; MWCSD: Ministry of Women, Community, and Social Development; PSC: Public Service Commission; SQA: Samoa Qualification Authority

\section{Acknowledgements}

We would like to fully acknowledge the Samoa country committee who dedicated their time and knowledge to implementing the Becoming Breastfeeding Friendly initiative: Maria Sanele, Namulauulu Tautala Maualaivao, Visesio Faaleaga, Saunimaa Aiolupotea, Jyothi Alex Abraham, Sina Tuautu, Cedrela Tamati, Patricia Lesatele, Naomi Harris, Samasoni Moala, Siaosi U Leleimalefaga, Lusi Faleupolu, Ulai Tapa Fidow, Acquin Time Fiu, Avai'a Tuilaepa Lautusi, Robyn Roache, Momoti Ulisese Tapuvae, Vaelei Apelu, Selaupasene Ualesi, and Christian Atoa.

We would like to deeply thank the Ministry of Health's Nutrition team (Darryl Pupi, Suauupaia Afitu, Lautala Malaga, Sofia Lolesio) also for supporting the implementation of this initiative. We would also like to thank Maee Ualesi Silva, and Courtney Choy for donating their time and effort to support this initiative.

\section{Authors' contributions}

The study was conceived and designed by RPE and AHF. The manuscript was drafted by CSU, NLH and AHF. All other authors participated in committee meetings and revised as well as approved the final manuscript.

\section{Funding}

The BBF project is funded by The Family Larsson-Rosenquist Foundation through a grant to Yale University (PI, Rafael Pérez-Escamilla). Yale University has received a one-off grant for BBF by the Family Larsson-Rosenquist Foundation. Selection of test sites for BBF has been within the sole and full discretion of Yale University. There is no agreement for follow-on funding based on results and all results of BBF must be made publicly available. The Family Larsson-Rosenquist Foundation is an independent foundation set up in 2013 by the Larsson family and it functions strictly in line with the Swiss law. The foundation pursues charitable objectives and acts completely independent from the companies it owns assets of. As such, no member of the board of the Family Larsson-Rosenquist foundation has a commercial role within the field of breastfeeding. The foundation owns the Olle Larsson Holding, which comprises several companies, including a property investment portfolio, and medical technology companies, such as Medela. Regardless of these assets, the foundation can receive funding from different sources.

\section{Availability of data and materials}

The datasets analyzed during the current study are available from the corresponding author on reasonable request.

\section{Ethics approval and consent to participate}

This study was exempt from human subjects' research review by Yale University's Institutional Review Board. The study did not recruit human subjects for any enquiries but rather this project includes expert opinion by public figures or program managers, which does not constitute the definition of human subjects' research at Yale. Thus, no formal ethics review was obtained for this study.

Consent for publication

Not applicable.

\section{Competing interests}

Dr. Rafael Pérez-Escamilla, Dr. Nicola Hawley, and Dr. Amber Hromi-Fiedler received salary support.

\section{Author details}

${ }^{1}$ Ministry of Health, Apia, Samoa. ${ }^{2}$ Yale School of Public Health, 60 College Street, New Haven, CT, USA.

Received: 23 July 2019 Accepted: 20 November 2019

Published online: 06 January 2020

References

1. Pérez-Escamilla P, Segura-Pérez S. Breastfeeding: a triple-duty action in the context of the double burden of malnutrition. Sight and Life. 2018;32(2):49-54. 
2. Victora C, Bahl R, Barros A. Breastfeeding in the 21st century: epidemiology, mechanisms, and lifelong effect. Lancet. 2016;387:475-90.

3. Bartick M, Reinhold A. The burden of suboptimal breastfeeding in the United States: a pediatric cost analysis. Pediatrics. 2010;125(5):e1048-56.

4. Muka T, Imo D, Jaspers L, Colpani V, Chaker L, van der Lee SJ, et al. The global impact of non-communicable diseases on healthcare spending and national income: a systematic review. Eur J Epidemiol. 2015;30(4):251-77.

5. Rollins NC, Bhandari N, Hajeebhoy N, Horton S, Lutter CK, Martines JC, et al. Why invest, and what it will take to improve breastfeeding practices? Lancet. 2016;387(10017):491-504.

6. Pérez-Escamilla R, Hall MV. Scaling up breastfeeding programmes in a complex adaptive world. Matern Child Nutr. 2016;12(3):375-80.

7. Pérez-Escamilla R, Hromi-Fiedler AJ, Gubert MB, Doucet K, Meyers S, Dos Santos Buccini G. Becoming Breastfeeding Friendly Index: Development and application for scaling-up breastfeeding programmes globally. Matern Child Nutr. 2018;14(3):e12596.

8. Pérez-Escamilla R, Curry L, Minhas D, Taylor L, Bradley E. Scaling up of breastfeeding promotion programs in low- and middle-income countries: the "breastfeeding gear" model. Adv Nutr. 2012;3(6):790-800.

9. Hromi-Fiedler AJ, Dos Santos BG, Gubert MB, Doucet K, Perez-Escamilla R. Development and pretesting of "Becoming Breastfeeding Friendly": Empowering governments for global scaling up of breastfeeding programmes. Matern Child Nutr. 2018;15:e12659.

10. Buccini G, Harding KL, Hromi-Fiedler A, Perez-Escamilla R. How does "Becoming Breastfeeding Friendly" work? A programme impact pathways analysis. Matern Child Nutr. 2018;15:e12766.

11. González de Cosío T, Ferré I, Mazariegos M, Pérez-Escamilla R. Scaling Up Breastfeeding Programs in Mexico: Lessons Learned from the Becoming Breastfeeding Friendly Initiative. Curr Dev Nutr. 2018; https://academic.oup. com/cdn/article/2/6/nzy018/4985833. Accessed 14 Oct 2019.

12. Aryeetey R, Hromi-Fiedler A, Adu-Afarwuah S, Amoaful E, Ampah G, Gatiba $\mathrm{M}$, et al. Pilot testing of the becoming breastfeeding friendly toolbox in Ghana. Int Breastfeed J. 2018;13:30.

13. Recommendations to promote breastfeeding in Germany. 2019. https//unw.gesundins-leben.de/_data/files/bbf_recommendations_germany.pdf. Accessed 9 Sept 2019.

14. Becoming Breastfeeding Friendly Scotland: Report. 2019. https://mwn.gov.scot/ publications/becoming-breastfeeding-friendly-scotland-report/, Accessed 9 Sept 2019.

15. Samoa National Health Strategy, 2008-2018. http://www.wpro.who.int/ health_services/samoa_nationalhealthplan.pdf, Accessed 13 Feb 2018.

16. World Health Organization, Western Pacific Region. Action Plan for Healthy Newborns in the Western Pacific Region (2014-2020). https://iris.wpro.who.int/ bitstream/handle/10665.1/10454/9789290616634_eng.pdf. Accessed 19 Apr 2019

17. FAO. Asia and the Pacific Regional Overview of Food Security and Nutrition 2018 Accelerating progress towards the SDGs. Bangkok: License: CC BY-NC-SA 3.0 IGO; 2018

18. Samoa Bureau of Statistics. Samoa: Demographic and Health Survey, 2014. https:/ www.sbs.gov.ws/digi/Samoa\%20DHS\%202014.pdf. Accessed 10 Sept 2019.

19. Hawley NL, Minster RL, Weeks DE, Viali S, Reupena MS, Sun G, et al. Prevalence of adiposity and associated cardiometabolic risk factors in the Samoan genome-wide association study. Am J Hum Biol. 2014;26:491-501.

20. Choy CC, Desai MM, Park JJ, Frame EA, Thompson AA, Naseri T, et al. Child, maternal and household-level correlates of nutritional status: a cross-sectional study among young Samoan children. Public Health Nutr. 2017;20(7):1235-47.

21. International Labour Organization. Maternity Protection Convention, 2000 (No. 183). https://www.lo.org/dyn/normlex/en/f?p=NORMLEXPUB:12100:0: NO::P12100_ILO_CODE:C183. Accessed 21 Feb 2019.

22. Kim JH, Shin JC, Donovan SM. Effectiveness of workplace lactation interventions on breastfeeding outcomes in the United States: an updated systematic review. J Hum Lact. 2018;35(1):100-13.

\section{Publisher's Note}

Springer Nature remains neutral with regard to jurisdictional claims in published maps and institutional affiliations.

Ready to submit your research? Choose BMC and benefit from:

- fast, convenient online submission

- thorough peer review by experienced researchers in your field

- rapid publication on acceptance

- support for research data, including large and complex data types

- gold Open Access which fosters wider collaboration and increased citations

- maximum visibility for your research: over $100 \mathrm{M}$ website views per year

At BMC, research is always in progress.

Learn more biomedcentral.com/submissions 